\title{
Fetal programming and its effects on vascular pulmonary circulation
}

\author{
Carmela Rita Balistreri \\ Department of Pathobiology and Medical Biotechnologies, University of Palermo, Palermo 90134, Italy.
}

Correspondence to: Dr. Carmela Rita Balistreri, Department of Pathobiology and Medical Biotechnologies, University of Palermo, Palermo 90134, Italy. E-mail: carmelarita.balistreri@unipa.it

How to cite this article: Balistreri CR. Fetal programming and its effects on vascular pulmonary circulation. Vessel P/us 2018;2:25. http://dx.doi.org/10.20517/2574-1209.2018.35

Received: 17 May 2018 First Decision: 8 Aug 2018 Revised: 17 Aug 2018 Accepted: 21 Aug 2018 Published: 19 Sep 2018

Science Editor: Alexander D. Verin Copy Editor: Yuan-Li Wang Production Editor: Zhong-Yu Guo

\begin{abstract}
Into the scientific community, consensus about the emerging concept of "the fetal origin of adult diseases" is growing. It sustains that the parental (of the two parents) adversities, and the related external influences, during the intra-utero/ perinatal life of each eutherian mammal organism, human included, can permanently set the structure and functionality of specific body systems (i.e., immune, endocrine, nervous and cardiovascular systems), predisposing them to early ageing and disease during adulthood. The pulmonary circulation system also appears to be one of its targets. Established evidence supports the strong association between developmental programming and pulmonary arterial remodeling and dysfunction. Here, a revised overview of this topic is reported, by stressing the efforts and advances in identifying the molecular and cellular mechanisms and pathways involved.
\end{abstract}

Keywords: Developmental programming, pulmonary circulation system, adult pulmonary arterial remodeling and dysfunction

\section{INTRODUCTION}

Lung represents an essential organ for human life, having an exclusive circulation system for functions and volume. Specifically, it has two circulations: the pulmonary and bronchial circulations ${ }^{[1]}$. Moreover, pulmonary arteries (PAs) and veins have two different functions: the gas replacement and oxygenation of blood, respectively ${ }^{[1]}$. In addition, pulmonary circulation has the distinctive feature of being able to accommodate the entire cardiac output, by preserving a high blood flow, but maintaining the intravascular arterial pressure at a reduced value. Another feature, which distinguishes the lung circulation system as unique, is the structure of arterial wall ${ }^{[1]}$. Accordingly, PAs have walls, which appear thinner than those

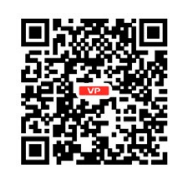


of systemic arteries, because of a reduced vascular smooth muscle component and a relative absence of adventitial components ${ }^{[1]}$. However, the lung circulation system has some factors able to control the pulmonary blood flow, like the systemic vascular system. They firstly include vascular structure, gravity, and mechanical effects of breathing ${ }^{[1]}$. Furthermore, neural and humoral factors are also involved.

Another feature of PAs is the susceptibility of pulmonary vascular tone for hypoxia ${ }^{[1]}$. Temporary hypoxia provokes pulmonary vasoconstriction, but, if persistent, it contributes to the onset of vascular remodeling and dysfunction, which results in the development of pulmonary hypertension $(\mathrm{PH})^{[2]}$. $\mathrm{PH}$ is defined by abnormally high pulmonary artery pressure, which can occur in numerous diseases and clinical situations. The hypoxemia represents one of the five major causes of PH. Accordingly, the 2015 ECS/ERS guidelines in the treatment and diagnosis of $\mathrm{PH}$ have assembled the different forms of $\mathrm{PH}$ related to diverse causes in five major groups ${ }^{[3]}$. Consistent with the recent guidelines, genetic and environmental factors represent other crucial factors of PH susceptibility. For example, pathogen infections [i.e., human immunodeficiency virus (HIV) infection] and the related inflammatory responses constitute the common causes of their onset, by altering the normal pulmonary endothelium barrier and causing edema ${ }^{[4,5]}$. Other inflammatory conditions not related to pathogens are also involved. For examples, autoimmune disorders, with a female predominance, are significantly associated with the onset of $\mathrm{PH}^{[5]}$. Regarding genetic factors, several research groups, from diverse European and US countries, have recently summarized all the established and emerging molecular defects related or not to familial pulmonary arterial hypertension (PAH) forms, which include not only mutations in the bone morphogenetic protein receptor type II (BMPR2) gene, defects of the transforming growth factor beta pathway, but also defects in activin A receptor type II-like 1 (ACVRL1), endoglin (ENG), and members of the SMAD family ${ }^{[6]}$.

Recently, Gao et al. ${ }^{[7]}$ have emphasized that an impairment of the normal development of pulmonary vasculature is involved in the pathogenesis of different paediatric pulmonary pathologies, PH included. In addition, they have particularly suggested that the principal target of this process is the endothelium. Accordingly, they have speculated that the identification of mechanisms and pathways, preserving both endothelial maturation and function, might improve the development of the entire lung. Furthermore, they also hypothesized that these mechanisms and pathways have long-term favourable effects in diverse forms of neonatal PH related not only to preterm birth and onset of lung diseases, but also to congenital heart diseases $^{[7]}$.

Consistent with these last findings, it appears reasonable that PH may also be the result of the developmental programming (DP) of adult diseases, as emphasized by fetal origin of adult diseases theory postulated by Barker $^{[8]}$. PH in neonates (PHN) has been demonstrated to be the result of several adverse events during intra-utero/perinatal life, including high-altitude living, maternal malnutrition, placental insufficiency related to environmental factors or diseases such as preeclampsia, infections (i.e., staphylococcus infection), drugs, alcohol, etc. ${ }^{[3]}$. Currently, the knowledge of the related mechanisms and pathways involved is imperative, because of the increased morbidity and mortality related to this $\mathrm{PH}$ group and the rise of prevalence in the new-borns, linked to the increase in unfavourable environmental factors in our populations. Their identification might facilitate the development of effective therapies or measures. Here, established literature evidence will be described and discussed.

\section{THE RELATIONSHIP BETWEEN DP AND PH: FOCUS ON EPIGENETIC FACTORS}

There is, in literature, a well-established evidence of DP in eutherian mammals, humans included. DP is the result of evolution's machinery, which determines, on the late, the utero and placentation development for guaranteeing an optimal intrauterine life ${ }^{[9]}$.

Accordingly, protection and nutritional support are the utero and placenta's functions. On the other late, 
this implies that foetal development happens by adapting to the micro-environment and maternal (or better paternal) endogenous and exogenous stressors. Consequently, both development and fate of tissues, organs, and systems of an offspring can result in an altered or greater susceptibility to onset of ageing and pathologies $^{[9]}$. The process of genomic imprinting is the principal driver of these alterations, and it consists of an uncommon epigenetic process ${ }^{[9]}$. It provides effects on new-borns, principally through maternal DNA methylation imprints. Today, other epigenetic mechanisms (i.e., histone modifications, antisense noncoding RNA (ncRNA)-mediated silencing, long-range chromatin interactions, and expression of microRNA), have been suggested to mediate genomic imprinting ${ }^{[9]}$. However, their actions remain unclear, even if it firstly supposes their capacity of modulating the expression of a wide range of imprinted genes restricted to specific foetal tissues, particularly the placenta, hypothalamus, and endothelium ${ }^{[9]}$. Contemporarily, the developing placenta and hypothalamus influence the expression of the foetal genome, which results in the release of hormones able to impact the functions of both foetal and maternal hypothalamus. This control consents the foetal hypothalamus to regulate the development of organs and systems of the foetus, such as the pulmonary circulation ${ }^{[9]}$. Maternal insults or stressors, including maternal nutritional changes, hormones (i.e., cortisol), other lifestyle stressors (e.g., obesity, smoking, drugs, alcohol), and the clinical status can alter maternal imprinting. This results in the onset of pathological conditions during pregnancy, including intrauterine growth restriction (IUGR) and preeclampsia ${ }^{[9]}$. On the other hand, IUGR and preeclampsia have been demonstrated to be significantly associated with the development of several pathologies in neonates, such as $\mathrm{PHN}^{[9]}$. IUGR neonates show prematurity and related immediate medical problems, and a notable susceptibility for hypertension, $\mathrm{PH}$, cardiovascular diseases, diabetes, and neurodegenerative diseases in adult age, likely through the effects of foetal programming.

\section{The principal target of foetal programming: the endothelium}

Endothelial dysfunction is the pathological condition associated with the onset of many pathologies related not only to the cardiovascular system, but also to the cardio-pulmonary circuit, as well as to developmental of disease in other tissues, principally correlated to the ageing process. This close relationship derives from the function of endothelium itself, which is the essential element of stroma of all tissues. Our and other groups emphasise this concept as being of great importance in understanding the complex pathophysiology of diseases, such as those of the cardiovascular and pulmonary systems ${ }^{[10-13]}$.

Endothelium has been demonstrated to be the major target of fetal programming. Its alterations and dysfunction primordially seem to originate from adverse parental and foetal environment conditions. Accordingly, recent experimental data have demonstrated that the levels of vascular endothelial growth factor (VEGF), its receptors and transcription factors, useful for the correct maturation and differentiation of foetal endothelium, are modulated by several adverse conditions, such as chronic hypoxia, maternal food restriction, altered levels of glucocorticoids, and microRNA ${ }^{[14]}$. Other findings report that chronic hypoxia and altered maternal clinical conditions can impact the maturation and differentiation of endothelium and the vasculature of all the tissue districts, ranging from foeto-placental arteries, carotid arteries, myocardium, to cerebrovascular systems, renal, liver, and PAs ${ }^{[15-17]}$. Another study also demonstrates that the IUGR condition in rats affects the function of both endothelium cells and their progenitors. Specifically, IUGR appears to induce vasodilatation, by modulating the expression and function of some molecules and pathways, such as acetylcholine and nitric oxide (NO) pathways, respectively ${ }^{[18]}$. Metabolic alterations related to IUGR condition have been also demonstrated to contribute to an altered development of endothelium and its dysfunction ${ }^{[19]}$. Musa et al. ${ }^{[20]}$, have recently reviewed the results from about 230 studies, on the key role of maternal and intrauterine conditions on endothelium structural and function of offspring, by reporting all the related alterations mechanisms and pathways involved.

\section{PHN AND FOETAL PROGRAMMING: FOCUS ON MECHANISMS AND PATHWAYS INVOLVED}

One of five PH groups, established by 2015 ECS/ERS 2015 guidelines $^{[3]}$, consists of PH diseases related to an 
Table 1. Mechanisms and pathways identified using apposite PHN models

\begin{tabular}{|c|c|}
\hline Mechanisms and pathways & Models \\
\hline $\begin{array}{l}\text { Functional reductions in soluble guanylyl cyclase (sGC) function and cyclic guanosine } \\
\text { monophosphate (cGMP)-dependent vasorelaxation }\end{array}$ & \multirow{5}{*}{$\begin{array}{l}\text { Utero ligation of the ductus } \\
\text { arteriosus and chronic perinatal } \\
\text { hypoxia in sheep fetuses and } \\
\text { newborns }\end{array}$} \\
\hline Increased phosphodiesterase type 5 (PDE5) and enhanced Endothelin-1 (ET-1) contraction; & \\
\hline Significant decrease of levels of endothelial nitric oxide synthase (eNOS) & \\
\hline Significant reduction in calcium activated potassium channels (BKCa) & \\
\hline Increase of these last molecules in chronic hypoxia & \\
\hline Important pulmonary arterial pressure $\left(P_{P A}\right)$ & \multirow{3}{*}{$\begin{array}{l}\text { Antenatal and/or postnatal hypoxic } \\
\text { exposure in mice }\end{array}$} \\
\hline Altered relaxation and augmented contractility of pulmonary arteries (PAs) & \\
\hline $\begin{array}{l}\text { Hyperplasia of pulmonary arterial smooth muscle cells (PASMCs) and improved actin } \\
\text { polymerization, and adventitial fibroblast proliferation. }\end{array}$ & \\
\hline $\begin{array}{l}\text { Rare group of the microvasculature and augmented smooth muscle actin expression in } \\
\text { distal PAs, changes that are associated with down-regulation of the bone morphogenetic } \\
\text { proteins (BMP) signaling pathway in affected lungs }\end{array}$ & \multirow[t]{2}{*}{$\begin{array}{l}\text { Short-term hyperoxia in mice: } \\
\text { a model of bronchopulmonary } \\
\text { dysplasia (BPD) }\end{array}$} \\
\hline Persistent alterations in lung structure. & \\
\hline $\begin{array}{l}\text { Vascular defects, predisposing the lung to } \mathrm{PH} \text { later in life, while in neonates it induces an } \\
\text { adaptive mechanism, which occurs in the right ventricular (RV) increasing the tolerance }\end{array}$ & Neonatal hyperoxia \\
\hline $\begin{array}{l}\text { Oxidative stress: high levels of reactive oxygen species (ROS) related to hyperoxia, } \\
\text { mechanical ventilation, hypoxia, and inflammation }\end{array}$ & \multirow[t]{2}{*}{$\begin{array}{l}\text { High altitude and assisted } \\
\text { reproductive technologies (ART) }\end{array}$} \\
\hline Epigenetic alterations & \\
\hline $\begin{array}{l}\text { Systemic vascular dysfunction in the progeny from both animals and humans. This seems } \\
\text { to be associated with an increase of ROS in placenta, which induce epigenetic alterations, } \\
\text { such as lung DNA methylation epigenetic mechanisms, such as an altered DNA } \\
\text { methylation and gene expressions of conserved pathways, such as Notch pathway }\end{array}$ & Maternal undernutrition \\
\hline $\begin{array}{l}\text { End-products of endothelial-derived nitric oxide (NO) heme-oxidation, nitrate and nitrite } \\
\text { produce exogenous NO, which mediates an increased vasoactive signaling activity during } \\
\text { hypoxia and stress }\end{array}$ & Alteration in maternal microbiome \\
\hline
\end{tabular}

altered development of pulmonary microvasculature, including PHN, which affects newborns. Offspring with PHN have aberrantly reactive or overly muscular vessels and show acute and chronic states of PHN, characterized by difficulty to adapt to breathing during the birth transition and early postnatal period. PHN is associated with a high morbidity and mortality ${ }^{[3]}$. The etiology's factors of PHN are diverse, ranging from high-altitude living, maternal malnutrition, placental insufficiency due to environmental factors or diseases, such as preeclampsia, to other pregnancy complications, such as infections (i.e., staphylococcus infection) or drugs $^{[3]}$. The number of newborns affected by PHN might increase, given the rise in adverse environmental factors or other causes in our Western society. Consequently, the investigations for identifying mechanisms and pathways are imperative. Of note are the experimental investigations on animal models, given the inadequate availability of patient tissues and inability to perform mechanistic studies in humans. Several animal PH's models have been developed for performing studies into the functional and structural changes, which occur during the development of pulmonary circulation and $\mathrm{PH}^{[21-34]}$. Unfortunately, to date not a single preclinical model perfectly replicates human PH. Nonetheless, the models used provide the opportunity to characterize the development and progression of $\mathrm{PH}$, to perform mechanistic studies, and to evaluate potential therapeutic treatments. In addition, the developed models could also permit to identify the mechanisms and pathways involved, which appear to be dependent on the type and grade of stress to which the fetus is subjected. They are illustrated in Table 1.

The multitude of models reported in literature is described in detail in the next paragraph, as well as the mechanisms and pathways identified and reported in Table 1.

\section{The relevant models for PHN}

Some relevant models for PHN have been developed and studied. Of note are the results obtained by the utero ligation of the ductus arteriosus and chronic perinatal hypoxia in sheep fetuses and newborns ${ }^{[22]}$. They have demonstrated that the mechanisms associated with $\mathrm{PH}$ are dependent on the type and grade of stress to which the fetus is subjected ${ }^{[22]}$. Specifically, similarities were observed between the ligation and 
hypoxia models, in functional reductions in soluble guanylyl cyclase (sGC) function, cyclic guanosine monophosphate (cGMP)-dependent vasorelaxation, increased phosphodiesterase type 5 (PDE5) and enhanced Endothelin-1 (ET-1) contraction. In contrast, significant differences were found in the cellular processes between the two models: a significant decrease in the levels of endothelial nitric oxide synthase (eNOS) and calcium activated potassium channels (BKCa) in ligation models; an increase of these molecules in chronic hypoxia ${ }^{[22]}$. Other models for PHN are the exposure-based models, including short-term neonatal hyperoxia, fetal and/or post-natal hypoxia and a two-hit model of prenatal hypoxia followed by postnatal hyperoxia. Among these, the antenatal and/or postnatal hypoxic exposure in mice are significantly associated with the onset of an important pulmonary arterial pressure $\left(\mathrm{P}_{\mathrm{PA}}\right)$, altered relaxation and augmented contractility of PAs, hyperplasia of pulmonary arterial smooth muscle cells (PASMCs) and improved actin polymerization, and adventitial fibroblast proliferation ${ }^{[23-25]}$. Short-term hyperoxia in mice, which is used as typical model of bronchopulmonary dysplasia (BPD), impacts the microvasculature and shows an augmented smooth muscle actin expression in distal PAs. These changes are also associated with the down-regulation of the bone morphogenetic proteins (BMP) signaling pathway in affected lungs ${ }^{[26]}$. Relevant are the recent findings on short-term neonatal exposure to hyperoxia. This condition is characterized to induce not directly $\mathrm{PH}$, but it may predispose adults to $\mathrm{PH}^{[27]}$, because of persistent alterations in lung structure. On the contrary, neonatal hyperoxia has been demonstrated to be advantageous for right ventricular (RV) hypertrophy. This has led to the hypothesis that this exposure shows two different effects: it can cause vascular defects, predisposing the lung to $\mathrm{PH}$ later in life, while in neonates it induces an adaptive mechanism, which occurs in the RV, increasing the tolerance ${ }^{[27]}$. Other models are the high altitude ${ }^{[28]}$ and assisted reproductive technologies $(\mathrm{ART})^{[29]}$, that have represented the models typically used by the Sartori group. They have consented to evidence the role of oxidative stress and/or epigenetic alterations during foetal programming and the altered onset of pulmonary circulation ${ }^{[30,31]}$. Consistent with these efforts and advances, reactive oxygen species (ROS) seem to have an important role in the pathogenesis of neonatal pulmonary vascular diseases, such as PHN. High levels of ROS may be produced in conditions of hyperoxia, mechanical ventilation, hypoxia, and inflammation. These data may be of crucial relevance in individuals born premature, who show a high risk of the long-term complications of pulmonary vascular diseases, thereby contributing to the increase of incidence of adult cardiovascular disease ${ }^{[32]}$. Maternal undernutrition ${ }^{[31]}$ during pregnancy has been used as another model for identifying the fundamental mechanisms, which occur in the altered development of pulmonary circulation and the onset of $\mathrm{PHN}^{[31]}$. This condition provokes systemic vascular dysfunction in the progeny from both animals and humans. Precisely, in rats, restrictive diet during pregnancy (RDP) raises oxidative stress in the placenta. ROS induce epigenetic alterations and can cross the placental barrier. An altered lung DNA methylation has been detected and is correlated with pulmonary vascular dysfunction. This datum has been confirmed using the treatment with histone deacetylase inhibitors butyrate and trichostatin A in RDP newborns ${ }^{[31]}$. These results suggest that the condition of undernutrition during gestation can contribute to an altered development of the cardiopulmonary system and the consequent onset of vascular dysfunction in the new generation through the actions of epigenetic mechanisms, such as an altered DNA methylation and gene expressions of conserved pathways, such as Notch pathway ${ }^{[31]}$. Accordingly, another investigation has evidenced the key importance of Notch pathway in the developmental alterations of cardiopulmonary circuit and the onset of $\mathrm{PHN}^{[33]}$. Recent evidence also underlines a key role of maternal microbiome in the onset of cardiac and pulmonary vascular diseases, such as $\mathrm{PHN}^{[34]}$. Specifically, it has been reported that end-products of endothelial-derived NO heme-oxidation, nitrate and nitrite produce exogenous NO, which mediates an increased vasoactive signaling activity during hypoxia and stress. The levels of nitrate and nitrite depend on the enzymatic reduction of nitrate to nitrite by bacterial nitrate reductase enzymes, expressed by precise bacterial gut populations ${ }^{[34]}$. Such as result, $\mathrm{PH}$ seems to be related to alterations in NO signaling, by suggesting a role of commensal oral bacteria in contributing to the onset of $\mathrm{PH}$ through the formation of nitrite, $\mathrm{NO}$ and other bioactive nitrogen oxides ${ }^{[34]}$. This evidence is supported by oral supplementation with inorganic nitrate or nitrate-containing foods, which are shown to have pleiotropic, useful vascular effects in the setting of inflammation, endothelial dysfunction, 
ischemia-reperfusion injury and in pre-clinical models of PH. Furthermore, the traditional high-nitrate diet is associated with beneficial outcomes in hypertension, obesity and cardiovascular diseases ${ }^{[34]}$.

\section{POTENTIAL MEASURES OF INTERVENTIONS FOR IMPROVING FOETAL PROGRAMMING AND THE DEVELOPMENT OF TARGET BODY SYSTEMS?}

It is well established that adverse events, taking place during the early periods of human development, mediate deleterious effects on health and disease molecular patterns of new progeny over his life course. This concept of health and disease origin ${ }^{[8]}$ is also leading to the study of the existence of relationships between the improving of foetal programming and the change of one determined lifestyle behaviour. For example, including the quantity of food intake and its quality, oral supplementation of prebiotics and/or probiotics, drug molecules, feeding preferences or willingness to engage in physical activities, etc. ${ }^{[35]}$. Beneficial results from use of their administration could lead to propose them as very programs of health, like to those recently projected by our institutions and organizations for improving "health" in our growing aged society having a high susceptibility for age-related diseases, such as cardiovascular diseases, pulmonary diseases, type 2 diabetes, cancer and neurodegenerative diseases. Certainly, their results could also prove unsuccessful because of the free will that characterizes the human nature in assuming choices on the behaviours to adopt. This limits their application, and it makes more difficult the understanding that the behaviours of everyone may also be the result of genetic and neurologic determinants mixed with the environment, during the process of neurodevelopment. Another limitation might be the choice of tool for measuring the consequent beneficial or lack of beneficial effects. One tool or parameter might be represented by fetal growth. Poor fetal growth is significantly associated with the onset of many diseases mentioned above. Specifically, IUGR represents a typical model, and is caused by, but not restricted to, placental insufficiency, maternal malnutrition and smoking, congenital infections and anomalies, drugs, obesity and chromosomal abnormalities. In low and middle-income countries, IUGR achieves the proportion of $27 \%$.

Some interventions are described in the subsequent paragraphs, stressing their advantageous effects.

\section{Physical activity}

Physical activity has been demonstrated to have many beneficial effects on diverse pathological conditions. In addition, it improves not only the physical health, but also the mental health. As stressed in my recent review, it represents a very useful intervention in old people ${ }^{[35]}$. In addition, exercise increases brain connectivity between the frontal, posterior, and temporal cortices, influences hippocampal volume and serum levels of brain-derived neurotrophic factor $(\mathrm{BDNF})^{[36]}$, a mediator of neurogenesis in the dentate gyrus of the hippocampus ${ }^{[36]}$. From a neurobiological standpoint, exercise modulates the production and release of cortisol, endocannabinoids, BDNF, dopamine and serotonin ${ }^{[36]}$. Specifically, the transient stress's response related to physical exercise evocates inhibitory effects from the secreted cortisol upon the hypothalamus and pituitary through medial prefrontal cortex receptors and reduces stress-induced over-excitability of the amygdala ${ }^{[35,36]}$. Moreover, aerobic exercise decreases the quantity of competitive amino acids during muscle uptake, and enhances tryptophan's chances of crossing the blood-brain barrier, and consequently it mediates the augmentation of serotonin, an important neurotransmitter for emotional processing, satiety and memory functions ${ }^{[35,36]}$. These might represent some of the potential targets of future research, particularly the study of the neurobiological effects of exercise in susceptible populations such as those born with IUGR ${ }^{[35,36]}$. Consequently, further research might benefit from recruiting IUGR individuals as appropriate subjects for evaluating interventions on physical activity in well designed, large-scale longitudinal studies, for detecting potential beneficial effects. Furthermore, basic neurobiological examinations on the effects of exercise in this group might also be performed. They could facilitate the identification of the mechanisms that better adapt to such interventions ${ }^{[35,36]}$. 


\section{Microbiome interventions}

Altered human microbiome, and particularly gut microbiome, is recognized to be significantly associated with the onset of various inflammatory diseases (i.e., age-related diseases) ${ }^{[35]}$. In addition, today, it is also linked with spontaneous preterm birth and other adverse pregnancy outcomes [Table 1]. Accordingly, it is suggesting that the administration of probiotics and/or prebiotics can ameliorate several immune and inflammatory parameters. This is demonstrating that manipulation of gut microbiome may result in beneficial effects ${ }^{[35]}$. In addition, a change in food intake and its quality are also proposed to be beneficial (see the next paragraph).

\section{Mediterranean diet}

The diet, and particularly the Mediterranean diet, represents a very advantageous intervention for the health of people, and some recent studies also confirm such relevance in both pregnancy and new-borns ${ }^{[35,36]}$. Accordingly, a recent investigation has evaluated the effects of adherence to a Mediterranean diet in 997 mother-child pairs from Project Viva in Massachusetts, USA, and 569 pairs from the Rhea study in Crete, Greece. This large study has demonstrated that greater adherence to Mediterranean diet during pregnancy may protect against cardio/pulmonary damage in offspring ${ }^{[37]}$. Similar data have been obtained in a study performed in 728 pregnant women who assumed a Mediterranean diet, and enrolled from TIMOUN Mother-Child Cohort Study conducted in Guadeloupe (French West Indies) between 2004 and $2007^{[38]}$. In addition, some studies suggest that the women who prepare for pregnancy, and particularly adolescent pregnancies, should benefit of an appropriate nutrition and diet for decreasing adverse maternal and newborn outcomes ${ }^{[39]}$. Although early life may be imperative for baby development, meticulous studies are essential to show the advantages to obtain using prenatal or postnatal diet's supplementation.

\section{Melatonin and metformin}

Useful results might derive by other approaches. Recently, it has been reported that the administration of antioxidants and anti-remodeling agents associated with the vasodilator therapies could have beneficial effects in new-borns ${ }^{[40-46]}$. From this point of view, melatonin (N-acetyl-5-methoxytryptamine, an indoleamine molecule), appears to be an effective agent for PHN, markedly improving pulmonary vascular function. However, the date until now obtained derive only from animal studies. Consequently, future studies should be performed for: (1) optimizing doses and/or therapeutic windows to improve the functional and anti-remodeling effects in animal models, as preclinical studies; and (2) extending these investigations to human pregnant women and new-borns ${ }^{[40-46]}$.

Another promising treatment might be the metformin, one drug normally used in diabetes therapy, even if its effects in pregnancy have been experimented only in the treatment of gestational diabetes ${ }^{[47]}$. Consequently, more studies are needed to provide more evidence for the future use of metformin.

\section{CONCLUSIONS AND PERSPECTIVES}

Growing evidence from epidemiological, clinical and experimental studies has clearly revealed a close relationship between adverse in utero environment and the augmented risk of diverse diseases, such as $\mathrm{PH}$ in later life ${ }^{[8]}$. Fetal stressors, such as hypoxia, high-altitude, malnutrition, and fetal exposure to nicotine, alcohol, cocaine and glucocorticoids can directly or indirectly act at cellular and molecular levels, by altering the cardio/pulmonary development and resulting in programming of heightened cardio/pulmonary vulnerability to diverse pathologies, such as $\mathrm{PH}^{[8]}$. The underlying mechanisms and pathways are not completely identified. However, crucial is the role of epigenetic mechanisms in fetal origin ${ }^{[9,48]}$. Predictably, pharmacological manipulations of epigenetic mechanisms present a promising interventional strategy. Indeed, several experimental studies in animals have offered exciting results, by using DNA methylation inhibitors and other agents, such as plant-derived isoflavone genistein, leptin, folate, fish oil, omega-3 and 
vitamin D. Specifically, they can alter the corresponding abnormal epigenetic modification status and improve the adverse programming effects caused by prenatal stress ${ }^{[49]}$. Advantageous effects have been obtained by modifying the diet and physical exercise, and performing interventions on the gut microbiome, as abovementioned. Furthermore, it has estimated, across gestation, that genetic and environmental influences vary during the various sensitive periods of pregnancy ${ }^{[50]}$. Accordingly, environmental factors have stronger influence on fetal growth at early end of first trimester, but are overtaken by genetic influences in late gestation. In addition, the fetal growth can be used as an optimal tool for measuring and estimating the effects.

Meticulous studies are indispensable to improve our knowledge in this field and the development of appropriate treatments, such as prenatal or postnatal supplementations. This might facilitate the reduction of the incidence and prevalence of this disease in new generations. Currently, such preventive measures are limited. However, it is well established until now that some surgical treatments, including both balloon pulmonary angioplasty (BPA) and pulmonary endarterectomy (PEA), can improve long-term survival, clinical status and hemodynamics in patients affected by this pathology. BPA is preferentially used for inoperable chronic thromboembolic pulmonary hypertension (CTEPH) or residual PH after PEA. PEA is, indeed, performed for operable CTEPH. Recent systematic reviews suggest their efficacy and safety ${ }^{[51,52]}$.

\section{DECLARATIONS}

\section{Authors' contributions}

The author contributed solely to the article.

\section{Availability of data and materials}

Not applicable.

\section{Financial support and sponsorship}

None.

\section{Conflicts of interest}

The author declared that there are no conflicts of interest.

\section{Ethical approval and consent to participate}

Not applicable.

\section{Consent for publication}

Not applicable.

\section{Copyright}

(c) The Author(s) 2018.

\section{REFERENCES}

1. Suresh K, Shimoda LA. Lung circulation. Compr Physiol 2016;6:897-943.

2. Tuder RM. Pulmonary vascular remodeling in pulmonary hypertension. Cell Tissue Res 2017;367:643-9.

3. Galiè N, Humbert M, Vachiery JL, Gibbs S, Lang I, Torbicki A, Simonneau G, Peacock A, Vonk Noordegraaf A, Beghetti M, Ghofrani A, Gomez Sanchez MA, Hansmann G, Klepetko W, Lancellotti P, Matucci M, McDonagh T, Pierard LA, Trindade PT, Zompatori M, Hoeper M. 2015 ESC/ERS Guidelines for the diagnosis and treatment of pulmonary hypertension: the joint task force for the diagnosis and treatment of pulmonary hypertension of the European Society of Cardiology (ESC) and the European Respiratory Society (ERS): endorsed by: Association for European Paediatric and Congenital Cardiology (AEPC), International Society for Heart and Lung Transplantation (ISHLT). Eur Respir J 2015;46:903-75. 
4. Guignabert C, Tu L, Girerd B, Ricard N, Huertas A, Montani D, Humbert M. New molecular targets of pulmonary vascular remodeling in pulmonary arterial hypertension: importance of endothelial communication. Chest 2015;147:529-37.

5. Batton KA, Austin CO, Bruno KA, Burger CD, Shapiro BP, Fairweather D. Sex differences in pulmonary arterial hypertension: role of infection and autoimmunity in the pathogenesis of disease. Biol Sex Differ 2018;9:15.

6. Machado RD, Southgate L, Eichstaedt CA, Aldred MA, Austin ED, Best DH, Chung WK, Benjamin N, Elliott CG, Eyries M, Fischer C, Gräf S, Hinderhofer K, Humbert M, Keiles SB, Loyd JE, Morrell NW, Newman JH, Soubrier F, Trembath RC, Viales RR, Grünig E. Pulmonary arterial hypertension: a current perspective on established and emerging molecular genetic defects. Hum Mutat 2015;36:1113-27.

7. Gao Y, Cornfield DN, Stenmark KR, Thébaud B, Abman SH, Raj JU. Unique aspects of the developing lung circulation: structural development and regulation of vasomotor tone. Pulm Circ 2016;6:407-25.

8. Barker DJ. The developmental origins of adult disease. J Am Coll Nutr 2004;23:588S-95S

9. Keverne EB. Genomic imprinting, action, and interaction of maternal and fetal genomes. Proc Natl Acad Sci U S A 2015;112:6834-40.

10. Balistreri CR (Ed.). Endothelial progenitor cells (EPCs) in ageing and age-related diseases: from their physiological and pathological implications to translation in personalized medicine. Mech Ageing Dev 2016;159:1-80.

11. Balistrieri CR. Endothelial progenitor cells. Basel: Springer International Publishing; 2017. p. 1-80.

12. Regina C, Panatta E, Candi E, Melino G, Amelio I, Balistreri CR, Annicchiarico-Petruzzelli M, Di Daniele N, Ruvolo G. Vascular ageing and endothelial cell senescence: molecular mechanisms of physiology and diseases. Mech Ageing Dev 2016;159:14-21.

13. Madonna R, Novo G, Balistreri CR. Cellular and molecular basis of the imbalance between vascular damage and repair in ageing and age-related diseases: as biomarkers and targets for new treatments. Mech Ageing Dev 2016;159:22-30.

14. Pearce WJ, Khorram O. Maturation and differentiation of the fetal vasculature. Clin Obstet Gynecol 2013;56:537-48.

15. Adeoye OO, Bouthors V, Hubbell MC, Williams JM, Pearce WJ. VEGF receptors mediate hypoxic remodeling of adult ovine carotid arteries. J Appl Physiol (1985) 2014;117:777-87.

16. Yzydorczyk C, Armengaud JB, Peyter AC, Chehade H, Cachat F, Juvet C, Siddeek B, Simoncini S, Sabatier F, Dignat-George F, Mitanchez D, Simeoni U. Endothelial dysfunction in individuals born after fetal growth restriction: cardiovascular and renal consequences and preventive approaches. J Dev Orig Health Dis 2017;8:448-64.

17. Muñoz-Muñoz EC, Krause BJ, Uauy R, Casanello P. LGA-newborn from patients with pregestational obesity present reduced adiponectin-mediated vascular relaxation and endothelial dysfunction in fetoplacental arteries. J Cell Physiol 2018;233:6723-33.

18. Oliveira V, de Souza LV, Fernandes T, Junior SDS, de Carvalho MHC, Akamine EH, Michelini LC, de Oliveira EM, Franco MDC. Intrauterine growth restriction-induced deleterious adaptations in endothelial progenitor cells: possible mechanism to impair endothelial function. J Dev Orig Health Dis 2017;8:665-73.

19. Menendez-Castro C, Rascher W, Hartner A. Intrauterine growth restriction-impact on cardiovascular diseases later in life. Mol Cell Pediatr 2018;5:4.

20. Musa MG, Torrens C, Clough GF. The microvasculature: a target for nutritional programming and later risk of cardio-metabolic disease. Acta Physiol (Oxf) 2014;210:31-45.

21. Berger J, Bhandari V. Animal models of bronchopulmonary dysplasia. The term mouse models. Am J Physiol Lung Cell Mol Physiol 2014;307:L936-47.

22. Papamatheakis DG, Chundu M, Blood AB, Wilson SM. Prenatal programming of pulmonary hypertension induced by chronic hypoxia or ductal ligation in sheep. Pulm Circ 2013;3(4):757-80.

23. Blood AB, Terry MH, Merritt TA, Papamatheakis DG, Blood Q, Ross JM, Power GG, Longo LD, Wilson SM. Effect of chronic perinatal hypoxia on the role of rho-kinase in pulmonary artery contraction in newborn lambs. Am J Physiol Regul Integr Comp Physiol 2013;304:R136-46.

24. Fediuk J, Sikarwar AS, Nolette N, Dakshinamurti S. Thromboxane-induced actin polymerization in hypoxic neonatal pulmonary arterial myocytes involves Cdc42 signaling. Am J Physiol Lung Cell Mol Physiol 2014;307:L877-87.

25. Yang Q, Lu Z, Ramchandran R, Longo LD, Raj JU. Pulmonary artery smooth muscle cell proliferation and migration in fetal lambs acclimatized to high-altitude long-term hypoxia: role of histone acetylation. Am J Physiol Lung Cell Mol Physiol 2012;303:L1001-10.

26. Yee M, White RJ, Awad HA, Bates WA, McGrath-Morrow SA, O’Reilly MA. Neonatal hyperoxia causes pulmonary vascular disease and shortens life span in aging mice. Am J Pathol 2011;178:2601-10.

27. Goss KN, Cucci AR, Fisher AJ, Albrecht M, Frump A, Tursunova R, Gao Y, Brown MB, Petrache I, Tepper RS, Ahlfeld SK, Lahm T. Neonatal hyperoxic lung injury favorably alters adult right ventricular remodeling response to chronic hypoxia exposure. Am J Physiol Lung Cell Mol Physiol 2015;308:L797-806.

28. Scherrer U, Allemann Y, Rexhaj E, Rimoldi SF, Sartori C. Mechanisms and drug therapy of pulmonary hypertension at high altitude. High Alt Med Biol 2013;14:126-33.

29. Allemann Y, Stuber T, de Marchi SF, Rexhaj E, Sartori C, Scherrer U, Rimoldi SF. Pulmonary artery pressure and cardiac function in children and adolescents after rapid ascent to 3,450 m. Am J Physiol Heart Circ Physiol 2012;302:H2646-53.

30. Sartori C, Rimoldi SF, Rexhaj E, Allemann Y, Scherrer U. Epigenetics in cardiovascular regulation. Adv Exp Med Biol 2016;903:55-62.

31. Rexhaj E, Bloch J, Jayet PY, Rimoldi SF, Dessen P, Mathieu C, Tolsa JF, Nicod P, Scherrer U, Sartori C. Fetal programming of pulmonary vascular dysfunction in mice: role of epigenetic mechanisms. Am J Physiol Heart Circ Physiol 2011;301:H247-52.

32. de Wijs-Meijler DP, Duncker DJ, Tibboel D, Schermuly RT, Weissmann N, Merkus D, Reiss IKM. Oxidative injury of the pulmonary circulation in the perinatal period: short- and long-term consequences for the human cardiopulmonary system. Pulm Circ 2017;7:55-66.

33. Hussain M, Xu C, Ahmad M, Yang Y, Lu M, Wu X, Tang L, Wu X. Notch signaling: linking embryonic lung development and asthmatic 
airway remodeling. Mol Pharmacol 2017;92:676-93.

34. Koch CD, Gladwin MT, Freeman BA, Lundberg JO, Weitzberg E, Morris A. Enterosalivary nitrate metabolism and the microbiome: intersection of microbial metabolism, nitric oxide and diet in cardiac and pulmonary vascular health. Free Radic Biol Med 2017;105:4867.

35. Balistreri CR. Anti-inflamm-ageing and/or anti-age-related disease emerging treatments: a historical alchemy or revolutionary effective procedures? Mediators Inflamm 2018;2018:3705389.

36. Nasello M, Schirò G, Crapanzano F, Balistreri CR. Stem cells and other emerging agents as innovative "drugs" in neurodegenerative diseases: benefits and limitations. Rejuvenation Res 2018;21:123-40.

37. Chatzi L, Rifas-Shiman SL, Georgiou V, Joung KE, Koinaki S, Chalkiadaki G, Margioris A, Sarri K, Vassilaki M, Vafeiadi M, Kogevinas M, Mantzoros C, Gillman MW, Oken E. Adherence to the Mediterranean diet during pregnancy and offspring adiposity and cardiometabolic traits in childhood. Pediatr Obes 2017;12:47-56.

38. Saunders L, Guldner L, Costet N, Kadhel P, Rouget F, Monfort C, Thomé JP, Multigner L, Cordier S. Effect of a Mediterranean diet during pregnancy on fetal growth and preterm delivery: results from a French Caribbean Mother-Child Cohort Study (TIMOUN). Paediatr Perinat Epidemiol 2014;28:235-44.

39. Christian P, Mullany LC, Hurley KM, Katz J, Black RE. Nutrition and maternal, neonatal, and child health. Semin Perinatol 2015;39:361-72.

40. Astorga CR, González-Candia A, Candia AA, Figueroa EG, Cañas D, Ebensperger G, Reyes RV, Llanos AJ, Herrera EA. Melatonin decreases pulmonary vascular remodeling and oxygen sensitivity in pulmonary hypertensive newborn lambs. Front Physiol 2018;9:185.

41. Torres F, González-Candia A, Montt C, Ebensperger G, Chubretovic M, Serón-Ferré M, Reyes RV, Llanos AJ, Herrera EA. Melatonin reduces oxidative stress and improves vascular function in pulmonary hypertensive newborn sheep. J Pineal Res 2015;58,362-73.

42. Maarman GJ. Natural antioxidants as potential therapy, and a promising role for melatonin against pulmonary hypertension. Adv Exp Med Biol 2017;967:161-78

43. Hung MW, Yeung HM, Lau CF, Poon AMS, Tipoe GL, Fung ML. Melatonin attenuates pulmonary hypertension in chronically hypoxic rats. Int J Mol Sci 2017;18:pii: E1125.

44. Sun H, Gusdon AM, Qu S. Effects of melatonin on cardiovascular diseases: progress in the past year. Curr Opin Lipidol 2016;27:40813.

45. Maarman G, Blackhurst D, Thienemann F, Blauwet L, Butrous G, Davies N, Sliwa K, Lecour S. Melatonin as a preventive and curative therapy against pulmonary hypertension. J Pineal Res 2015;59:343-53.

46. Jin H, Wang Y, Zhou L, Liu L, Zhang P, Deng W, Yuan Y. Melatonin attenuates hypoxic pulmonary hypertension by inhibiting the inflammation and the proliferation of pulmonary arterial smooth muscle cells. J Pineal Res 2014;57:442-50.

47. Zhu B, Zhang L, Fan YY, Wang L, Li XG, Liu T, Cao YS, Zhao ZG. Metformin versus insulin in gestational diabetes mellitus: a metaanalysis of randomized clinical trials. Ir J Med Sci 2016;185:371-81.

48. Wang Y, Yan L, Zhang Z, Prado E, Fu L, Xu X, Du L. Epigenetic regulation and its therapeutic potential in pulmonary hypertension. Front Pharmacol 2018;9:241.

49. Li Y, Gonzalez P, Zhang L. Fetal stress and programming of hypoxic/ischemic-sensitive phenotype in the neonatal brain: mechanisms and possible interventions. Prog Neurobiol 2012;98:145-65.

50. Workalemahu T, Grantz KL, Grewal J, Zhang C, Louis GMB, Tekola-Ayele F. Genetic and environmental influences on fetal growth vary during sensitive periods in pregnancy. Sci Rep 2018;8:7274.

51. Tanabe N, Kawakami T, Satoh T, Matsubara H, Nakanishi N, Ogino H, Tamura Y, Tsujino I, Ogawa A, Sakao S, Nishizaki M, Ishida K, Ichimura Y, Yoshida M, Tatsumi K. Balloon pulmonary angioplasty for chronic thromboembolic pulmonary hypertension: a systematic review. Respir Investig 2018;56:332-41.

52. Tromeur C, Jaïs X, Mercier O, Couturaud F, Montani D, Savale L, Jevnikar M, Weatherald J, Sitbon O, Parent F, Fabre D, Mussot S, Dartevelle P, Humbert M, Simonneau G, Fadel E. Factors predicting outcome after pulmonary endarterectomy. PLoS One 2018;13:e0198198. 